\title{
Narrating the Law: Possibilities, Pitfalls and Prospect
}

\author{
Leon Wolff \\ Faculty of Law, Bond University, University Drive \\ Robina 4229 Queensland, Australia \\ lwolff@bond.edu.au
}

ABSTRACT

This article explores the possibilities and limits of using narrative analysis as a sociolegal method to illuminate issues of law and justice. It defines narrative analysis, explores the different ways the method has been used in the social sciences, and critically evaluates its use in interdisciplinary research on sexual harassment.

Keywords: narrative analysis, sexual harassment, socio-legal research methods

\section{INTRODUCTION}

Narrative approaches to socio-legal research questions in the legal academy are rare. This omission, I submit, is puzzling. Narrative analysis seems well-suited to much work on law and society. After all, socio-legal research interrogates how people experience and engage with the law; and, as Paton observes, "[t]he central idea of narrative analysis is that stories and narratives offer especially translucent windows into cultural and social meanings."[1] Further, narrative analysis enjoys prominence in the social sciences generally and growing acceptance in critical legal scholarship in the United States. Following a long tradition in literary studies dating back to Russian formalism in 1928, narrative analysis emerged in social sciences in the 1980s and entrenched itself as a popular method by the 1990s. [2, 3] In American critical legal studies, it is a commonly employed by legal feminists $[4,5,6,7,8]$ and critical race theorists. [5, $9,10,11,12,13,14]$

So why is it absent in law-and-society scholarship? Rather than proffer any excuses or explanations, my aim in this paper is more modest: to explore the extent to which, if at all, narrative analysis may enrich research on issues of law and society. In large part, this article is a private journey. As a scholar on comparative sexual harassment law, $[15,16,17,18,19,20]$ I am interested in whether the narrative approach can inform my future work. As such, I will focus my reflections on two existing narrative studies of sexual harassment: one by a legal scholar,[21] the other by non-law scholars.[22] From this private review, however, I hope to yield public results, generating broader lessons for the socio-legal and comparative law research community on the possibilities and pitfalls of narrative analysis.

This is a much harder task than it first appears. Despite its growing popularity in social research and critical legal studies, much about narrative analysis - what it is and what it entails - is uncertain. As Abell notes, "[a]lthough the term narrative and cognate concepts ... are widely used ... no settled definition is yet established."[23: at 288] Czarniawska goes further[2: at 660]:

In my rendition, narrative analysis does not have a 'method'; neither does it have a 'paradigm', a set of procedures to check the correctness of its results. It gives access to an ample bag of tricks - from traditional criticism through formalists to deconstruction - but it steers away from the idea that a 'rigorously' applied procedure would render 'testable' results. 
This is not necessarily a weakness. Indeed, in this paper, I will argue that the open-endedness of narrative analysis is precisely what gives it its power. But, as my review of the two sexual harassment studies reveals, it does impose a special responsibility on researchers to justify their use of the narrative approach, be transparent about their methods, and take care with how far they generalise their findings, if they want their research results to convince.

\section{WHAT IS NARRATIVE ANALYSIS? \\ Data sources, epistemology and researcher role}

Put simply, narrative analysis is the analysis of people's stories.[1, 24, 25] Social science researchers study these stories because they offer insights into how people understand and experience the world.[26, 27] As Cronon explains:[28:at 1349]

Narrators create plots from disordered experience, give reality a unity that neither nature nor the past posses so clearly. In so doing, we move well beyond nature into the intensely human realm of value.

Data typically comes from oral sources, such as interviews,[21] oral histories and sermons.[29] But written sources may also reveal narratives, such as diaries,[14] letters,[27] trial transcripts[30, 31] and newspaper accounts. Although most researchers locate narratives within qualitative data,[24] Elliott[3] has recently proposed that quantitative data collected using sample methods, especially longitudinal data, may also be rich with narrative potential.

Epistemologically, narrative analysis assumes that meanings are fluid and contextual,[27] not fixed and universal:[2: at 651]

... [N]arrative knowledge tells the story of human intentions and deeds, and situates them in times and space. It mixes the objective and the subject aspects, relating the worlds as people see it, often substituting chronology for causality. In contrast the logico-centric knowledge looks for cause-effect connections to explain the world, attempts to formulate general laws from such connections, and contains procedures to verify/falsify its own results.

Narrative analysis presumes a self-consciously involved - rather than a detached researcher. To capture people's ordinary experiences without disturbing their narrative character, the researcher must blend empathy with description and interpretation.[27] More profoundly, the researcher's "voice, presence and subjectivity" will infuse the analysis,[25: at 475] as will their "meta-stories" of personal values, politics and theoretical commitments.[27, 32] Researchers may even go so far as to cooperate with participants in gathering and reflecting on data.[21]

\section{ANALYTICAL METHODOLOGY}

There is no set procedure for analysing and interpreting narratives. Researchers agree that narrative "imposes order on a flow of experiences" and its analysis involves mapping out "how it is put together, the linguistic and cultural resources it draws on and how it persuades a listener of authenticity"; [27] they differ, however, on how to do this.[2] Techniques range from formal analytic narrative, narrative explanation, narrative structural analysis and sequence analysis to poetics, hermeneutic triad and deconstruction.

Table 1 summarise some of the more formal approaches to narrative analysis. Some formalists such as Labov[33] argue that narratives are best understood in terms of their structural properties; others, such as Burke,[34] understand narratives by reference to the grammatical 
resources that narrators draw on to shape their stories; and yet others[35] rely on lexical techniques - especially the figurative and tropological use of language - to interpret narratives. Researchers working in a more oral tradition analyse pitch and pauses, and use poetic units, stanzas and strophes to examine the coherence, organization and meaningfulness of talk.[27]

Table 1: Formalist approaches to narrative analysis

\section{Structural properties}

Abstract (summary of the substance of the narrative);

Orientation (time, place, situation, participants);

\section{Complicating action \\ (sequence of events);}

Evaluation (significance and meaning of the action, attitude of the narrator);

Resolution (what finally happened); and

Coda (the return of the perspective to the present)

\section{Grammatical resources \\ Act (what was done?) \\ Literary use of language \\ Metaphors}

Scene (when or where was it done?)

Agent (who did it?)

Agency (how he/she did it?)

Purpose (why?)
Irony (view from the opposite, sometimes incongruous or paradoxical side

Synechdote (linking instances to a larger concept)

\section{Metanomy}

(representing a whole in terms of one of its parts)

A more layered approach to narrative analysis looks beyond meaning (semantics) and structure (syntax) to include interactional context (pragmatics).[3] This analysis additionally focuses on the relationship between the narrator and his/her audience to reveal meanings about social and personal relations.[3,27] It may also takes into account the broader context, such as the historical moment, race, class and gender.[27] This approach is depicted in Figure.

Figure 1: A multi-layered approach to narrative analysis

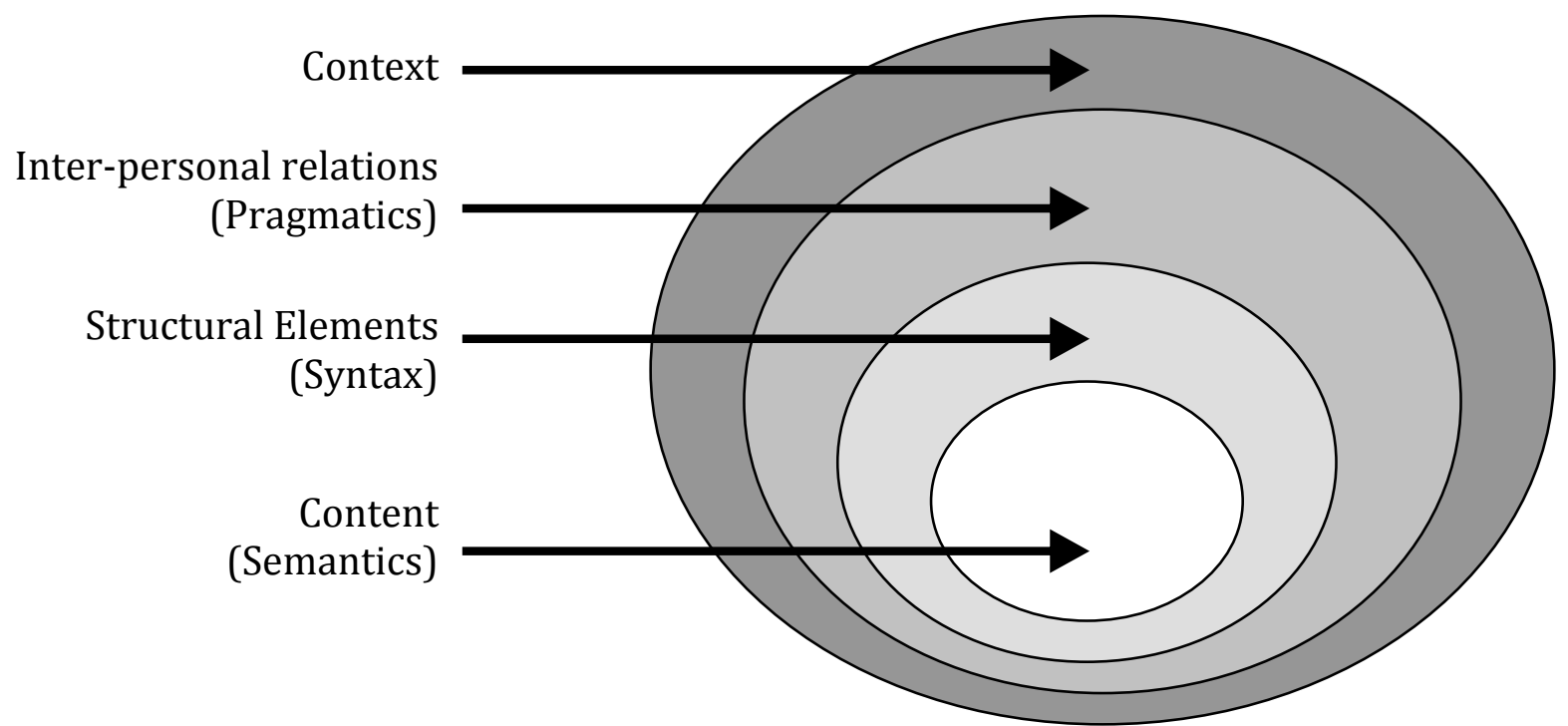

Post-modern and post-structural scholars may rely more on perspective or deconstruction. Hernadi,[36] for example, develops a hermeneutic triad as follows: 
o Stand under the text (that is, understand or explicate the text);

o Stand above the text (that is, explain or disassemble the text to see how it is made); and

o Stand in for the author (that is, explore or bring one's own life and preoccupations into the text).

Martin[37] relies on deconstruction techniques such as locating hidden ideologies and false dichotomies in the narratives.

\section{Comparison With Other Methods}

A key advantage of narrative analysis over other qualitative methods is that it does not fragment the data.[29] Traditional approaches to qualitative analyses fracture texts in the service of interpretation and generalisation, eliminating the sequential and structural features that characterize narrative accounts and coding responses out of context.[27] Drawing on Patton[1] and Punch,[29] Table 2 summarises this and other key points of distinction between narrative analysis and other common qualitative methods.

Table 2: Differences between narrative analysis and other qualitative methods Qualitative methods Points of distinction from narrative theory

Grounded theory Grounded theory writers are aware of the problem of fragmentation and decontextualization and suggest ways of recombing and recontextualizing the data. But narrative analysis deals more holistically with qualitative data right from the start.

Ethnography

Hermeneutics

Phenomenology

Case study
Ethnography develops accounts which assume that language is transparent and can create stable, singular meanings. Narrative is about interpreting interpretations and gives prominence to human agency and imagination.

Although both methods shares an emphasis on interpretation, narrative analysis extends beyond texts to life histories, interview transcripts, historical memoirs and non-fiction writing.

Although both methods place emphasis on understanding lived realities and perceptions of experience, narratives are not a documentary of experience.

Narrative analysis focuses on events, not cases. Narrative analysis is not constrained by the program or system under review.

\section{NARRATIVE ANALYSIS IN SEXUAL HARASSMENT RESEARCH \\ Uses of Narrative Analysis}

The diversity of approaches to narrative analysis is matched by the diversity of uses to which the method is put. The two articles the subject of this paper are good examples. One[21] uses narratives to explain the litigation choices of sexually harassed women; the other,[22] to explore the ways in which sexual harassment is a structural and cultural element of academia. This illustrates how the narrative analytic method can be flexibly - and powerfully moulded to answer a variety of research questions.

Morgan's study[21] examines the narratives of thirty-one sexually harassed women. The thirty-one narratives were recounted by women who had reported their sexual harassment to the authorities. The dominant characteristics of those women interviewed were a general lack 
of financial resources, lack of experience with litigation, and the responsibility for the care or support of dependants (such as partners and children). Of the sample group, all of the 31 women considered bringing legal action, but only 3 actually did so. Examining the narratives in question, Morgan concludes from the references to husbands, children and parents that "relationality played an important, and often pivotal, role in the choices these women made."[21: at 86]

Taylor and Conrad[22] interpret 36 first-hand anonymous accounts by both perpetrators and victims of sexual harassment in an academic environment. They cite as their methodology a close reading of the text in an attempt to inductively generate common themes. The narratives indicate, they argue, "that academic departments are pervaded by a male sexuality as an 'open secret' reinforced by 'a conspiracy of silence."'[22: at 407]

\section{Evaluation}

One of the strengths of narrative analysis is that it provides rich insight into social life.[2, 29] This is because of the authenticity that comes from respondents being empowered to tell their own stories in their own words. It also comes from analysing stories holistically rather than fragmenting the data.[29] Morgan, for example, relied on unstructured interviews with 13 of her respondents to allow her subjects to speak in their voice and raise issues that they felt were important to them. In addition, she recorded conversations among 18 other women who participated in a victim's self-help group, but was uninvolved in setting the discussion agenda. Likewise, Taylor and Conrad drew on 36 first-hand accounts of sexual harassment in which the authors were asked to share their experiences rather than respond to any pre-defined topics or issues.

However, as Elliott notes,[3] narrative methods are more useful for constructivist research questions (what an experience means to subjects) rather than realist questions (what is the state of reality). Narrators necessarily distort reality because they are making sense of, rather than reporting on, the real world. On this front, Morgan's study suffers, since she is seeking to "explain" why victims of sexual harassment choose to litigate, whereas Taylor and Conrad make more effective use of the method by studying the cultural values and power relations inherent in universities that foster sexual harassment.

Constructivist research questions are also helpful in combating one the key weaknesses of the narrative approach - the generalisability of its findings. As Neuman writes, "the narrative plot is embedded in a complex constellation of particular details, making universal generalizations difficult."[25: at 475] However, as Elliott rebuts,[3] narrative research will degenerate into mere description unless researchers are allowed to draw broader inferences from their work. Constructivism - a focus on inter-subjective meanings rather than the interior life of the individual - is one way to ensure the robustness of inferences, but Elliott also recommends that researchers:[3]

o take care to note the temporal and historical contingencies of their research;

0 ensure against reifying language; and

o broaden their sample, even though (given how time intensive narrative analysis is, it will always be selective).

Both sexual harassment studies do not fully satisfy Elliott's tests of robustness. While Taylor and Conrad, at least, are concerned with inter-subjective meanings (that is, how broader cultural values inform the stories victims tell about their sexual harassment experiences), they seek to explicate the broader sexual harassment culture of "academic departments" rather than that of the specific department of the specific university at the specific point of time of the 
study (importantly, the 1970s and 1980s when sexual harassment was a relatively new phenomena). Further, they rely on narratives by academics but not students or general staff. Morgan's study is even weaker. She, too, draws broad inferences about the litigation choices of sexually harassed "women", even though:

o her sample of low-income earners excludes African-American women and professional women; and

o her analysis is directed to individual choices rather than shared meanings.

Even worse, she reifies language by noting the multiple mentions of family relationships, yet fails to accord any significance to the subjects' evident lack of economic autonomy and financial resources both at home and in the workplace, rendering suspect her conclusion that relationality trumps resources in explaining the litigation choices of victims.

The context-specific nature of narratives, therefore, is key to any evaluation of narrative studies. First, it informs which types of research questions are better suited to narrative inquiries (constructivist rather than realist). Second, it highlights the possibilities and pitfalls of the method: on the one hand, narratives add authenticity by drawing on fully-drawn accounts of lived experiences; on the other, they confound generalisations. This discussion might be recast in more traditional terms - that is, that narrative inquiries have "reliability" insofar as they are directed to issues of inter-subjectivity; that they score well on "internal validity"; but that they are more problematic on "external validity". Some proponents of narrative research, such as Elliott,[3] believe that these traditional tests, if appropriately modified, are useful measures of the quality of narrative studies.

Other scholars fiercely disagree. Neuman,[27] for example, dismisses the relevance of reliability. Narrative research, after all, looks at evolving, fluid, historically contingent and context-specific accounts of experience; it is not designed to deliver stable findings. In a similar vein, a number of scholars[38, 39.40] have attempted to develop alternative quality frameworks for qualitative studies, but none directly targets the evaluation of narrative inquiries. Only Riessman[25] has developed a nuanced framework for addressing the relative merits of narrative-based scholarship. Rejecting "formulas and recipes", Riessman cites "trustworthiness" as the central criterion in her framework.[25] Her framework is summarised in Table 3 below.

\section{Table 3: Riessman's Framework for Evaluating Trustworthiness of Narrative Inquiries}

\section{Step \\ Persuasive and plausible Correspondence}

Coherence

Pragmatic

\section{Elements}

Findings are supported by evidence Alternative explanations are considered. Results are taken back to those studied (member checks)

Interpretation is constrained by three levels of the text to avoid ad hoc theorizing:

- global (speaker's beliefs and goals)

- local (structure of the narratives)

- themal (recurrent themes that unify the text)

Extent to which the research can become the basis for others' work

- description of how the interpretations were produced

- specification of successive 
transformations of the data

- availability of the primary data;

- explicit statement of the researcher's

foundational assumptions and values

Applying this framework, Morgan's study is riddled with problems. Despite seeking feedback on her interpretations from her subjects and involving two of those who provided the most detailed feedback in the actual research process (correspondence), her work suffers from a lack of transparency (pragmatism). She furnishes insufficient information about the background of the women interviewed so it is difficult to assess how representative or otherwise her sample group might be. She does not make her data available (for example, in an appendix); fails to explain how she interpreted the narrative accounts beyond identifying "multiple references"; and quotes selectively in order to back up her claims of relationality. Her conclusions are not particularly convincing either because, while highlighting the relationality aspects of the accounts, she fails to consider alternative explanations inherent in the accounts (coherence), such as the subjects' overt lack of social and economic power (persuasive and plausible).

Taylor and Conrad fare a little better. First, they explicitly state their assumptions about gender and sexuality in the workplace and identify the problems they faced as white men dealing with an issue that overwhelmingly affects women; they also reproduce the full text of the narratives they rely upon (pragmatic). Second, they reported their interpretations to successive meetings in their department for "feedback" (coherence), although they do not explain how they elicited this feedback and what they did with it in their analysis. However, like Morgan, the authors do not explain their interpretative strategy and how they reached their conclusions (pragmatic). Further, their conclusions were more theory-driven rather than supported by quotes from the original narrative stories (persuasive and plausible).

\section{IMPLICATIONS FOR ALAW-AND-SOCIETY RESEARCH}

So what can socio-legal scholars take from this overview of narrative analysis and a critical review of its strengths and weaknesses? Certainly, narrative analysis opens up exciting new avenue of inquiry for scholars in law and society. Although the two articles under review focus on oral transcripts, others show that there is rich narrative potential within written sources easily accessible to the legal researcher, such as trial transcripts and judgments.

The multiple ways of conducting narrative analysis offers promise as well as sounds a warning. While it means researchers are free to explore techniques on their own terms and in accordance with the imperatives of their research question, they do need to carefully document their research process to ensure trustworthiness. Due diligence, it seems, is a priority not only for trial lawyers but also for narrative-focused legal research scholars!

\section{REFERENCES}

1. Patton, M.Q. 2002. Qualitative research and evaluation methods ( $3^{\text {rd }} \mathrm{ed}$ ). London: Sage.

2. Czarniawska, B. 2004. The uses of narrative in social science research. In: Hardy, M. \& Bryman, A., ed. Handbook of data analysis. London: Sage, 649-666.

3. Elliot, J. 2005. Using narratives in social research. London: Sage.

4. Flagg, B. 1990. Women's narratives, women's story. University of Cincinnati Law Review, 59, 147-168.

5. Harris, A. 1990. Race and essentialism in feminist legal theory. Stanford Law Review, 42(3), 581-616.

6. Scheppele, K.L. 1987. The re-vision of rape law. University of Chicago Law Review, 54, 1095-1116. 
7. Scheppele, K.L. 1988. Foreword: Telling stories. Michigan Law Review, 87, 2073-2098.

8. Scheppele, K.L. 1992. Just the facts, ma'am: Sexualized violence, evidentiary habits, and the revision of truth. New York Law School Law Review, 37, 123-172.

9. Delgado, R. 1988. Storytelling for oppositionists and others: A plea for narrative. Michigan Law Review, 87, 2411-2441.

10. Delgado, R. 1991a. Beyond critique: Law, culture, and the politics of form. Texas Law Review, 69, 19291983.

11. Delgado, R. 1991b. Campus antiracism rules: Constitutional narratives in collision. Northwestern University Law Review, 85, 343-387.

12. Delgado, R. 1995. Rodrigo's Final Chronicle: Cultural power, the law reviews, and the attack on narrative jurisprudence. Southern California Law Review, 68, 545-575.

13. Delgado, R. 1999. Making pets: Social workers, 'problem groups,' and the role of the SPACA - Getting a little more precise about racialized narratives. Texas Law Review, 77, 1571-1584.

14. Williams, P.J. 1991. The Alchemy of Race and Rights: Diary of a Law Professor. Cambridge, Mass: Harvard University Press.

15. Parker, C. \& Wolff, L. 2000. Sexual harassment and the corporation in Australia and Japan" The potential for corporate governance of human rights. Federal Law Review, 28(3), 509-548.

16. Parker, C. \& Wolff, L. 2002. Corporate governance and human rights. In: Bottomley, S. \& Kinley, D., ed. Commercial law and human rights. Aldershot: Ashgate, 135-160.

17. Wolff, L. 1996. Eastern twists on Western concepts: Equality jurisprudence and sexual harassment in Japan. Pacific Rim Law \& Policy Journal, 5(2), 509-535.

18. Wolff, L. 2000. Private governance of public rights in Japan: Revisiting the Japanese governance debate. Pacific Economic Papers, 302, 3.1-3.27.

19. Wolff, L. 2002. Governance and human rights in Japan. In: Sampford, C., Condlln, S., Palmer, M, Round, T., ed. Asia Pacific governance: From crisis to reform. Aldershot: Ashgate, 287-306.

20. Wolff, L. 2003. Japanese women and the 'new' administrative state. In: Amyx, J. \& Drysdale, P., ed. Japanese governance: Beyond Japan, Inc. London \& New York: RoutledgeCurzon, 156-169.

21. Morgan, P. 1999. Risking relationships: Understanding the litigation choices of sexually harassed women. Law and Society Review, 33, 67-89.

22. Taylor, B. \& Conad, C. 1992. Narratives of sexual harassment: organizational dimensions. Journal of Applied Communication Research, 20, 401.

23. Abell, P. 2004. Narrative explanation. Annual Review of Sociology, 30, 287-310.

24. Bryman, A. 2004. Social Research Methods (2nd ed). Oxford: Oxford University Press.

25. Neuman, W. 2006. Social research methods: Qualitative and quantitative approaches (6th ed). Boston: Pearson.

26. Hinchman, L. P. \& Hinchman, S. K. 1997. Introduction. In: Hinchman, L. P. \& Hinchman, S. K., eds, Memory, identity, community: the idea of narrative in the human sciences. New York: State University of New York, ixvi.

27. Reissman, C. 1993. Narrative analysis. Newbury Park: Sage.

28. Cronon, W. 1992. A place for stories: Nature, history, and narrative. Journal of American History, 78(4), 1347-1376.

29. Punch, K. 2005. Introduction to social research: Quantitative and qualitative approaches (2 ${ }^{\text {nd }}$ ed). London: Sage.

30. Burns, C. 2004. Constructing rape: judicial narratives on trial. Japanese Studies, 24(1), 81-96.

31. Burns, C. 2005. Sexual violence and the law in Japan. London \& New York: RoutledgeCurzon.

32. Wood, J. 1992. Telling our stories: Narratives as a basis for theorizing sexual harassment. Journal of Applied Communication Research, 20, 349-362. 
33. Labov, W. 1997. Some further steps in narrative analysis. The Journal of Narrative and Life History, 7 (14), 395-415.

34. Burke, K. 1945. A grammar of motives. Los Angeles: University of California Press.

35. Miles, M.B. \& Huberman, A.M. 1994. Qualitative data analysis ( $2^{\text {nd }}$ ed). Thousand Oaks, CA: Sage.

36. Hernadi, P. 1987. Literary interpretation and the rhetoric of the human sciences. In: Nelson, J. S., Megill, A. and McCoskey, D. N., eds, The rhetoric of the human sciences/ Madison: University of Wisconsin Press, 263-75.

37. Martin, J. 1990. Deconstructing organizational taboos: The suppression of gender conflict in organizations. Organizational Science, 1(4), 339-359.

38. Fade, S.A. 2003. Communicating and judging the quality of qualitative research: The need for a new language. Journal of Human Nutrition \& Dietetics, 16, 139-149.

39. Mays, N. \& Pope, C. 2000 .Qualitative research in health care: Assessing quality in qualitative research. $B M J, 320,50-52$.

40. Meyrick, J. 2006. What is good qualitative research? A first step towards a comprehensive approach to a judging rigour/quality. Journal of Health Psychology, 11(5), 799-808. 